\title{
EDUCAÇÃO E EMANCIPAÇÃO NA TEORIA CRÍTICA DA SOCIEDADE DE THEODOR W. ADORNO
}

\author{
Cleidson de Jesus Rocha ${ }^{1}$ \\ Universidade Federal do Acre (UFAC) \\ Universidade de São Paulo (USP) \\ https://ordic.org/0000-0001-7535-1110 \\ E-mail: cleidson.ufac@gmail.com
}

\section{RESUMO:}

Este artigo apresenta a contribuição de Theodor W. Adorno para a configuração de uma educação capaz de enfrentar os irracionalismos contemporâneos, por meio de uma retomada da definição da dialética como crítica do pensamento filosófico. Este tem, modernamente, se limitado a enlevar a racionalidade à máxima potência, sem se debruçar sobre os efeitos de suas promessas não cumpridas. A obra de Adorno é reconhecida por uma propugnação segundo a qual cabe à filosofia a tarefa da reflexão crítica e do esclarecimento da forma como a cultura se organiza. Tal proposição leva a um projeto teórico que pressupõe a tomada de consciência sobre os descaminhos da razão, numa tentativa de que, por intermédio do esclarecimento, o homem possa construir possibilidades de autonomia e emancipação. $\mathrm{O}$ artigo se organiza em duas partes, assim apresentados: 1. Ambições tórico-práticas da teoria crítica da sociedade e 2) Fios que tecem a teoria crítica de T. W. Adorno, este dividido em três tópicos: a) $O$ clima cultural geral do capitalismo tardio - a propensão à barbárie; b) Falência da cultura - razão objetiva da barbárie; c) Reflexos da vida danificada: o adoecimento do contato.

PALAVRAS-CHAVE: Educação e Emancipação; Teoria Crítica; Adorno.

\section{EDUCATION AND EMANCIPATION IN THE CRITICAL THEORY OF THE SOCIETY OF THEODOR W. ADORNO}

\begin{abstract}
:
This article presents the contribution of Theodor W. Adorno to the configuration of an education capable of confronting contemporary irrationalism, through a resumption of the definition of dialectics as a critic of philosophical thought. It has modernly limited itself to rationalizing rationality to the highest power, without dwelling on the effects of its unfulfilled promises. The work of Adorno is recognized by a propensity according to which it is the responsibility of philosophy to critically reflect and clarify the way culture organizes itself. Such a proposition leads to a theoretical project that presupposes an awareness of the misconceptions of reason, in an attempt that, through enlightenment, man can construct possibilities of autonomy and emancipation. The article is organized in two parts, as follows: 1. Theorical-practical ambitions of the critical theory of society and 2) The threads that weave TW Adorno's critical theory, divided into three topics: a) The general cultural climate of late capitalism - the propensity for barbarism; b) Bankruptcy of culture - objective reason of barbarism; c) Reflexes of damaged life: the sickness of contact.
\end{abstract}

KEYWORDS: Education and Emancipation; Critical Theory; Adorno.

\footnotetext{
${ }^{1}$ Doutor em Filosofia. Professor da Universidade Federal do Acre (UFAC), Cruzeiro do Sul - AC, Brasil. Estágio pós-doutoral na Universidade de São Paulo (USP), São Paulo - SP, Brasil.
}

ROCHA, Cleidson de Jesus. Educação e emancipação na teoria crítica da sociedade de Theodor W. Adorno. Griot : Revista de Filosofia, Amargosa - BA, v.19, n.2, p.194-217, junho, 2019. 


\section{Introdução}

No que concerne à relação entre educação e emancipação do homem, vários elementos da obra de Adorno nos ajudam neste debate. Em primeiro lugar, o fato de ter se ocupado tão sistematicamente com a crise da cultura, demonstrando a extensão da vertiginosa inovação tecnológica, com implicações determinantes da difícil situação em que se encontram os sistemas educativos. Em segundo lugar, não seria preciso muita argumentação para propor a releitura de um dos autores que mais se esforçou por compreender as raízes do fascismo e analisar suas consequências, precisamente quando, hoje, no cenário internacional, o terrorismo toma o lugar da lógica e impõe uma ética da vingança em vez de uma ética da tolerância e no cenário nacional, se apresenta o esboço de um projeto de educação voltado a consagrar políticos de direita, sem a consideração mínima sobre o que seja legal e/ou ético, querendo fazer valer as mais espúrias narrativas sobre os fracassos do sistema de ensino, reportando aos professores e ao pensamento crítico as históricas mazelas da educação.

Vemos, nos escritos de Adorno sobre a esfera da educação, a constante preocupação com a não repetição das atrocidades cometidas no campo de concentração de Auschwitz. Sua defesa é de uma educação contra a barbárie, tendo sempre os acontecimentos de holocausto como o máximo exemplo da necessidade da afirmação de um novo imperativo moral que norteie o trabalho educativo. Mantém-se, no centro das preocupações de Adorno, a defesa de uma educação contra a violência e que sirva aos propósitos da afirmação da auto emancipação do homem. Para tanto, faz-se imprescindível o exercício da crítica, que terá como elementos a própria realidade histórica, seus acontecimentos e a análise dos modos pelos quais se impõe o clima cultural geral da sociedade atual, que gera uma mentalidade homogênea e linear em todos os grupos.

Os interesses de Adorno voltam-se para a promoção da razão emancipatória, tarefa esta que deverá ser cumprida pela teoria crítica, como denúncia dos irracionalismos - entre eles os acontecimentos de Auschwitz - por intermédio da afirmação de uma dialética negativa.

De alguma maneira se faz necessário que a esfera da educação retome a tarefa de recuperação da definição da dialética de Hegel e que Adorno pretendeu encarnar de maneira radical: a dialética é o espírito de contradição organizado; o cuidado de romper as limitações da consciência tradicional, de ajudar a fazer com que o oculto salte à luz. Essa tarefa encontra na esfera da educação espaço privilegiado para ser levada à frente. Isso exige dos envolvidos com funções educativas o cuidado de se precaver contra as conceitualizações aparentes, que dissimulam a verdadeira realidade dos fatos. Além disso, impõe a responsabilidade da análise interna da educação e sua relação com a sociedade, seu movimento real, aquele que fica obscuro quando utilizamos conceitos que, por seu caráter necessariamente determinante, se fossilizam em identidades abstratas. Nos escritos de Adorno: “o urgente para o conceito é aquilo a que não se chega, o que o mecanismo da sua abstração elimina, o que não é de antemão um caso de conceito" (ADORNO, 1975, p. 16). 
Filipe Ceppas, falando especificamente sobre o ensino de filosofia, defende que o potencial da teoria crítica pode contribuir para a melhoria da formação, aumentando, assim, as possibilidades de se imprimir, no ensino, o critério da crítica, indispensável para as transformações qualitativas do processo formativo.

\begin{abstract}
Ao enfrentar a questão do esclarecimento e da emancipação, a teoria crítica (de Adorno) ajuda diretamente, portanto, na reflexão de propostas de ensino [...] que pretendem enfrentar [...], nos limites do trabalho docente, o problema das promessas não cumpridas de aperfeiçoamento humano associados à formação (Bildung), enquanto processo cultural sistemático de apreensão, síntese e realização de valores herdados e em constante transformação; processo no qual se pode reconhecer, historicamente, e ao menos nominalmente, o predomínio da valorização da razão e do pensamento crítico. Acima de tudo, enquanto esforço sistemático de trabalho intensivo com uma noção de crítica que se quer própria ao estágio atual da reflexão filosófica, o pensamento (...) pode interessar mais de perto, evidentemente, a professores e pensadores que ainda esperam encontrar nesta noção um apoio conceitual relevante para a teoria e a prática do ensino (CEPPAS, 2003, p. 73).
\end{abstract}

Além das questões acima descritas por Filipe Ceppas, outras tantas justificariam a verificação sistemática do trabalho de Adorno no tocante à educação. Para Ilan Gur-Ze'ev (2004) embora o pensamento de Adorno tenha sido atacado pelos próprios teóricos críticos como um pensamento que se protege da prática, as ideias da fase final de sua produção "poderiam ter sido, e ainda podem ser possibilidades abertas para a criação de uma batalha contra-educacional genuína, de um tipo que transcenderia o que tem sido feito na Pedagogia Crítica hegemônica" (GUR-ZE'EV, p. 14) ${ }^{2}$. Para este autor, os trabalhos em que Adorno se refere explicitamente à educação escolarizada e acadêmica, são ensaios com o mesmo nível de rigor teórico daqueles mais conhecidos, porém dotados de um caráter mais negativista. Nestes escritos Adorno argumenta que o grande obstáculo para a mente crítica e para uma educação humanista não é, necessariamente, a alienação, mas o desaparecimento da consciência desta no interior da totalidade, que se governa pela racionalidade instrumental. Quer dizer: o espírito crítico se exila e "a ultrapassagem do abismo entre a substância e o sujeito se trivializa", (GUR-ZE'EV, p. 30) e o espírito se iguala "às representações dominantes como 'realidade', 'normalidade' e máquina de prazer a qual a educação homogeneizadora rapidamente se adapta" (GUR-ZE'EV, p. 30) Neste sentido, para Gur-Ze'ev não se justificam as críticas a Adorno, mormente ao fato de ele ter abandonado à crítica marxista tradicional ${ }^{3}$. Para o próprio Adorno (2000, p. 206) a ideologia hoje é a própria sociedade. E é para esta que Adorno aponta seu rigor crítico-negativo.

\footnotetext{
2 Na década de 1960, Adorno proferiu um conjunto de conferências sobre o papel da educação, algumas delas retransmitidas via rádio, que depois foram reunidas em uma publicação, que no Brasil ganhou o título de Educação e Emancipação, com tradução do professor Wolfgang Leo Maar, publicada pela Editora Paz e Terra, 1995.

3 O conjunto da produção conhecida como "teoria crítica", vigorosamente desenvolvida pelos autores frankfurtianos, tinham em comum o distanciamento de uma analítica economicista, dos moldes marxianos, para uma análise dos desenvolvimentos e feições da cultura, que, em seu caráter técnico, passou a cumprir o papel de dominação sistemática dos grupos.
}

ROCHA, Cleidson de Jesus. Educação e emancipação na teoria crítica da sociedade de Theodor W. Adorno. Griot : Revista de Filosofia, Amargosa - BA, v.19, n.2, p.194-217, junho, 2019. 
Filipe Ceppas, justificando a importância do trabalho de Adorno sobre a educação diz também que

\begin{abstract}
A questão da educação pode ser situada no centro da filosofia adorniana, em primeiro lugar porque grande parte de sua produção sobre a música e a arte em geral, que ocupa diversos volumes de suas obras publicadas, está diretamente relacionada à questão da formação, articulando-se a aspectos fundamentais de sua perspectiva filosófica central, a dialética negativa. Além do mais, toda a preocupação com a situação do pensamento nas sociedades de massa têm, para Adorno, uma direta relação com os processos formativos (ou deformativos) da e na cultura, em seus mais diversos âmbitos [...] (CEPPAS, 2003, p. 73-74).
\end{abstract}

\title{
Ambições teórico-práticas da Teoria Crítica da Sociedade
}

A obra de Adorno é amplamente reconhecida por uma propugnação segundo a qual cabe à filosofia, em cooperação com as ciências, a tarefa da reflexão crítica e do esclarecimento da cultura sobre ela mesma. Essa opção teórico-metodológica leva a um projeto teórico que pressupõe a tomada de consciência sobre os descaminhos da razão, numa tentativa de que, por intermédio do esclarecimento, o homem possa construir possibilidades de autonomia e de emancipação.

A discussão sobre emancipação tem modernamente, em Kant, sua principal referência, pois é com este autor que o conceito de esclarecimento ganha contornos de um saber público, como mediação entre a política e a moral. $O$ autor alemão Immanuel Kant (1985) apresenta a célebre definição do lema do esclarecimento: Sapere Aude ("Ousar Saber"), nas seguintes palavras:

Esclarecimento (Aufklarung) é a saída do homem de sua menoridade, da qual ele próprio é culpado. A menoridade (Unmündigkeit) é a incapacidade de fazer uso de seu entendimento sem a direção de outro indivíduo. $O$ homem é o próprio culpado dessa menoridade se a causa dela não se encontra na falta de entendimento, mas na falta de decisão e coragem de servir-se de si mesmo sem a direção de outro. Sapere Aude! Tem coragem de fazer uso de seu próprio entendimento, tal é o lema do esclarecimento. (KANT, p. 100, 1985)

Do ponto de vista do indivíduo, a ideia de libertar-se dessa imaturidade auto imputável indica uma máxima subjetiva: pensar por conta própria. Considerandose a humanidade como um todo, apresenta-se como uma tendência objetiva a necessidade de que ela experimente o progresso e que assim, conheça uma ordem humana justa. Trata-se da habilitação da razão humana, como principal instrumento de humanização e transformação do homem em sujeito da própria história e construtor de saídas para a humanidade. $\mathrm{O}$ desdobramento desse projeto, tem, no século XVIII, com o projeto iluminista, seu triunfo e glória, com a exaltação da razão humana como instrumento de libertação e autonomia humana.

Segundo Ernest Cassirer, a força e a natureza do século das luzes, a sua verdadeira questão, pode ser sintetizada em um nome: razão. 


\begin{abstract}
A razão é o ponto de encontro e o centro de expansão do século, a expressão de todos os seus desejos, de todos os seus esforços, de seu querer e de suas realizações. [...] O século XVIII está impregnado de fé na unidade e imutabilidade da razão. A razão é uma e idêntica para todo o indivíduo [...], para todas as nação, todas as épocas, toda a cultura. (...) A razão define-se muito menos como uma possessão do que como uma forma de aquisição. (CASSIRER, 1992, p. 22-23)
\end{abstract}

A função da razão é cumprir o papel crítico-reflexivo, como um procedimento analítico e construtivo por meio do qual é possível o retorno "transparente" da cultura sobre ela mesma. A opacidade e a violência provenientes de conceitos, práticas e valores que se pretendem válidos inquestionavelmente, são devidamente desencantados e deslegitimados pela função crítica da razão.

No resgate que os frankfurtianos fazem do legado da ilustração, eles se interessam sobretudo pela articulação entre intenção emancipatória e razão reflexiva. A emancipação por via da ilustração requer a vontade de ser racional. A ideia da razão inclui a vontade de alcançar a autonomia e a responsabilidade na direção da própria vida. A autonomia, conceito central para a filosofia clássica alemã, representa para o indivíduo ou grupo social o telos de um processo de formação. Nesse sentido, podemos resgatar o conceito de formação como constituição da racionalidade e da sensibilidade enquanto faculdades essencialmente morais, e não como simples aprisionamento de habilidades instrumentais/técnicas.

A teoria crítica da sociedade de T. W. Adorno aborda, de forma central, o problema do esvaziamento da capacidade crítica no sujeito contemporâneo e a maneira como a epistemologia tradicional trata a questão do conhecimento. Os fins e os meios pelos quais a ciência se desenvolve são questionados, especialmente os daquela ciência que se modelou conforme os princípios do positivismo e do cientificismo, vistos por Adorno como a consciência mutilada da atual civilização. O positivismo, em sua pretensão de objetividade, acaba, segundo Adorno, promovendo uma redução arbitrária da realidade, que resulta num empobrecimento das múltiplas dimensões desta, já que para este interessam apenas os aspectos quantificáveis. A consequência disso é que, assim sendo, o universal, que é a atividade abstrata do sujeito, se impõe ao particular. A universalidade abstrata devora o particular em nome de uma necessidade que não é a da razão, mas que procede da irracionalidade. Esta metodologia, baseada em procedimentos redutores do real, acaba atingindo as ciências sociais, que retrocedem na consideração de que o indivíduo pode ser dono de uma identidade forjada pelo meio social, que espera uma perfeita sintonia de pensamento e ação de seus membros. Ao tratar as pessoas desta maneira, o positivismo liquida o espaço do indivíduo, subtraindo sua autonomia e desintegrando-o enquanto sujeito.

Para além dessas questões, a teoria crítica de T. W. Adorno se opõe a teoria tradicional da sociedade e, embora não apresente um corpus alternativo de doutrinas, se expressa por meio da crítica a diversas correntes de pensamento. Adorno não perde de vista a ideia de uma intervenção na ordem social, que pudesse ser construída com os auspícios de uma ciência engajada em promover as mudanças que a sociedade almeja. Uma ciência assim, obviamente, necessitaria compreender 
os mecanismos falseadores da condição humana plena. Dessa maneira, deve compreender e desnudar o pensamento ideológico, que volta-se contra a "alteridade", reduzindo violentamente a realidade à sua própria imagem e semelhança. Para Adorno, a ideologia é uma forma de pensamento de identidade um estilo veladamente paranoico de racionalidade, que transmuta inexoravelmente a singularidade e a pluralidade das coisas em mero simulacro de si ou que as expulsa para além de suas fronteiras, em um ato de exclusão dominado pelo pânico. Por isso, o oposto da ideologia não seria a verdade ou a teoria, mas a diferença ou a heterogeneidade.

A teoria crítica de Adorno pretende desnudar a pretensão positivista de afirmação de uma pretensa verdade fenomênica. Para isso, considera a necessidade do uso de uma dialética, desde que esta liberte o pensamento de um teor identificante, positivo, caracterizando-se, antes, como negativa. Adorno afirma a não-identidade essencial do pensamento e realidade, do conceito e seu objeto. Imaginar, por exemplo, que a ideia de liberdade é equivalente aquela que o mercado capitalista propõe ou divulga, é deixar de perceber que esse objeto não está à altura do seu conceito. De maneira inversa, imaginar que o ser de qualquer objeto pode ser esgotado pelo seu conceito é apagar sua materialidade única, já que os conceitos são inelutavelmente gerais e os objetos teimosamente particulares.

Dessa maneira, Adorno defende uma mudança fundamental na ordem discursiva-conceitual da epistemologia. A identidade, aos seus olhos, é a forma primordial de toda ideologia, devendo, por isso mesmo, ser negada. O princípio da identidade, defendido, entre outros, por Hegel, luta por suprimir toda a contradição. $O$ mundo burocratizado do capitalismo avançado aperfeiçoou este processo, reduzindo as potencialidades dos indivíduos, que se transformam em meros exemplares de uma espécie que já não dá conta de remar contra a correnteza para reagir contra o princípio da dominação.

A dialética negativa, assim, ao apoiar-se no que há de utópico, denuncia, ao mesmo tempo, o caráter afirmativo da cultura do capitalismo avançado, que é falso enquanto advoga a aceitação de um modo de organização econômico-cultural como prática coletiva, totalizante, portanto. A dúvida quanto à positividade desse tipo de sociedade se sustenta a partir de um constante movimento de todas as energias humanas para contradizer o real. Para Adorno, o espírito deve refletir sem descanso sobre a contradição do real para poder organizar-se segundo a forma da contradição. $O$ ponto de partida para o exercício do pensamento negativo é a compreensão de que a realidade é, de fato, tanto a soma dos sujeitos quanto sua negação. Os indivíduos jamais se realizam plenamente como sujeitos, mas são na consideração de suas perdas, das subtrações a que são submetidos, nos planos e sonhos que se concretizam e dos que se esvaem. Na equação do que se é e do que se perde, os sujeitos se constituem como agentes, e no conjunto, como as gentes. Compreender a lógica da reprodução subjetiva do processo material e social de produção é o apoio necessário para a instauração da crítica, com a qual se realiza a dialética negativa. Esta opera com a lógica da desagregação: ao invés de esconder, dissimular, faz eclodir e revela a contradição. Por esse motivo é adequada no tratamento das contradições do capitalismo avançado e justifica-se a si mesma, já que "uma situação justa não necessitaria dela" (ADORNO, 1975, p. 19). 


\section{Fios que tecem a Teoria Crítica de T. W. Adorno}

\section{O clima cultural geral do capitalismo tardio: a propensão à barbárie}

Conforme Jürgen Habermas (1975), a partir do século XVIII, se estende a formação social do capitalismo liberal e com essa formação aumenta a suscetibilidade de que este sistema caia numa crise sistêmica, pois se intensificam as tensões entre as relações que se entretecem nos subsistemas sociais (o subsistema econômico, o político e o sociocultural), cujas articulações permitem conjugar as tendências às crises que surgem. Assim no capitalismo tardio:

[...] as tendências às crises econômicas são deslocadas [...] ao sistema político. (Neste) surge um feixe de tendências a crises que [...] se caracterizam pelo fato de que podem substituir-se reciprocamente dentro de certos limites. Estes limites estão determinados, por uma parte, pela massa de valores que podem obter-se mediante o sistema tributário [...] e, por outra parte, pelo aprovisionamento de motivações de parte do sistema sociocultural. [...] Quanto menos capaz se mostra o sistema cultural de prover motivações suficientes aos sistemas político, de educação e de profissões, tanto mais deve substituir o "sentido" escasso por valores consumíveis (que procedem do sistema econômico) (HABERMAS, 1975, p. 37-38).

Este deslocamento das tendências sistêmicas às crises, que permitem um afundamento definitivo da formação social, tem, como indica a citação anterior de Jürgen Habermas, importante implicação no fator cultural. Nessa formação social, densa em inter-relações e entrelaçada por crises que vão se despejar nos diversos subsistemas, a angústia pela falta de clareza com relação ao futuro se faz inevitável. A nebulosidade com relação ao futuro, se apresenta na homogeneização de pensamentos e ideias, uma vez que todos os indivíduos encontram-se acachapados por uma mentalidade homogênea, não criativa, estacionária, construída com os auspícios da grande máquina de fazer cultura, chamada por Adorno e Horkheimer de Indústria Cultural. ${ }^{4}$

Segundo Wolfgang Leo Maar (1997, p. 45) o instrumento maior de manipulação dos sujeitos é a indústria cultural, que é "oriunda do processo valorativo da produção capitalista tardia", e que "produz um objeto que conduz a sua crítica ao abismo". Esse instrumento tão poderoso utilizado pelo sistema capitalista é responsável pela imposição de um clima cultural marcado pela simiformação. Seu resultado mais dramático é a impressão da falta de capacidade para a crítica e a aceitação da aparência como realidade. Segmenta-se, então, uma espécie de espírito objetivo negativo. A formação cultural, assim, se converte em uma semiformação socializada, disposta a controlar o espírito contemporâneo. Ela não antecede à formação cultural, mas a sucede. A consciência como definida pelo

\footnotetext{
4 Na obra escrita a quatro mãos, intitulada Dialética do Esclarecimento, escrita por Adorno e Horkheimer, encontra-se o capítulo "Indústria Cultural: o esclarecimento como mistiticação das massas", no qual os autores apresentam a forma de operação da indústria cultural enquanto instrumento de elaboração, divulgação e massificação dos produtos culturais, responsáveis pela formação do pensamento reificado, próprio da sociedade do capitalismo avançado.
} 
iluminismo, renuncia à autodeterminação, prendendo-se, de maneira obstinada, a elementos culturais aprovados. Toda a ilustração e toda a informação que se difundem, não são suficientes para evitar a disseminação da semiformação, que passou a ser a maneira dominante da consciência atual.

O pensamento, assim definido, considera apenas suas determinações parciais, enquanto carrega a pretensão de sua própria verdade. Nesse sentido, ele é, de certo modo, paranoico, "a sombra do conhecimento" (ADORNO e HORKHEIMER, 1985, p. 182). Quando o ato cognitivo carrega a marca da projeção, reboca o risco de absolutizar-se, de se transformar em delírio paranoico. É o que acontece no anti-semitismo: indivíduos ligados em comunidades de aliança voltados para a propagação do terror às pessoas de fora do grupo. Outro aspecto da dinâmica do anti-semitismo consistia na liquidação da consciência moral em razão da necessidade, prescrita pela sociedade totalitária, de o indivíduo se orientar unicamente pelas ordens impostas a ele pelo sistema. Esse sistema, que vai ganhando abrangência, alcança seu ponto máximo com os campos de concentração nazistas.

Para Adorno, o ápice do declínio do espírito objetivo é representado pelos acontecimentos de Auschwitz, um nexo exemplar entre cultura e sociedade, extremo exemplo do nível de extinção da capacidade de racionalização a que chegaram os tempos modernos. Segundo o Comitê Internacional de Dachau (1979) ao menos desde 1933 tiveram início os assassinatos em campo de concentração de Dachau, próximo de Munich. Nos anos seguintes se abriram novos Campos: Auschwitz, Mauthausen, Bergen-Belsen, Belzec, Sobibór, Treblinka, etc., que, com o tempo, se tornaram campos de extermínio. O conceito "Auschwitz", utilizado por Adorno, se refere a esse conjunto de campos de extermínio e, ao mesmo tempo, se coloca como representação única da barbárie absoluta. Segundo Leo Maar, (2003, p. 60) Auschwitz "representaria (...) o ponto de fuga de uma 'cultura' meramente expressiva e sem a dimensão crítica, que em seu limite conduz a uma situação em que tanto a própria cultura se dissolve, quanto à sociedade e a política". Leo Maar se refere aqui ao fato de Auschwitz determinar a afirmação da ideologia como uma "primeira natureza". É a ideologia tomada como vida, se é que se pode considerar vida a experiência da passagem por Auschwitz, já que ali a vida é reduzida à mera sobrevivência e a morte campeia como parte elementar da vida. Auschwitz não se caracteriza pela morte, mas pela barbárie de fazer habitar no espaço entre a vida e a morte milhões de pessoas, que perdem, assim, sua condição humana. Adorno representa uma espécie de última fronteira a repensar a relação razão e barbárie no seu extremo, vivida até a raiz de sua angústia, por meio de uma consciência incomodada, as contradições vivas de uma modernidade que parece não querer sarar suas feridas explorando qualquer solução imediatista.

Para Primo Levi (1988) o campo de concentração é um espaço sem tempo, um lugar, um campo também no sentido da Física, uma representação cujos pontos estão submetidos a forças heterogêneas. Para este autor,

Não há tempo em Auschwitz (e por isso não há memória). (...) A memória é um instrumento curioso: desde que estou no campo, me tem passado pela cabeça os versos escritos por um amigo meu há muito tempo: “... e basta que um dia / dizer manhã já não terá nenhum 
sentido". Aqui é assim. Sabeis como se diz sempre na fala do campo?

“Morgen früh", manhã por manhã (LEVI, 1988, p. 119).

Apenas o medo, impresso pela negação da vida, unia os elos das vidas que se esvaíam a cada instante. Para Adorno,

\begin{abstract}
A identidade (de Auschwitz) está na não-identidade, no que ainda não se passou, que denuncia o que se passou. A afirmação de que as coisas são sempre as mesmas é falsa na sua imediatidade [...]. Quem se deixa arrancar o reconhecimento do aumento do horror entrega-se não somente a uma contemplação insensível, mas não consegue compreender, junto com a diferença específica entre os acontecimentos mais recentes e os antecedentes, a verdadeira identidade do todo, do terror sem fim (ADORNO, 1993, p. 205-206).
\end{abstract}

Esse alerta de Adorno dá-se em função da pouca consciência que hoje se tem em relação à exigência da não repetição de Auschwitz e as questões que ela levanta. Daí sua convicção de que a monstruosidade desse fato não calou fundo nas pessoas, constituindo-se um sintoma da persistência da possibilidade de que se repita, no que depender do estado de consciência das pessoas. O não rompimento radical com as condições que geraram Auschwitz é, assim, uma das principais bandeiras levantadas por Adorno, motivo pelo qual luta em favor de uma maior visibilidade dos infortúnios e contra a pressão social, que continua se impondo. Segundo Adorno (1995, p. 120) os escritos de Freud, especialmente os ensaios $O$ mal-estar na cultura e Psicologia de massas e análise do eu, merecem a mais ampla divulgação, uma vez que aí se encontra o debate de que a civilização origina e fortalece, progressivamente, o que é anticivilizatório: a barbárie encontra-se no próprio princípio civilizatório. Uma tomada de posição crítica capaz de enfrentar esse clima cultural geral propício à barbárie seria a expressão plena da emancipação. Esse quadro, porém, está longe de se esboçar. Por isso Adorno alerta:

O fato de milhões de pessoas inocentes [...] terem sido assassinadas de uma maneira planejada, não pode ser minimizada por nenhuma pessoa viva como sendo um fenômeno superficial, como sendo uma aberração no curso da história, que não importa, em face da tendência dominante do progresso, do esclarecimento, do humanismo supostamente crescente. $\mathrm{O}$ simples fato de ter ocorrido já constitui por si só expressão de uma tendência social imperativa (ADORNO, 1995, p. 120).

Apesar das óbvias indicações da possibilidade da repetição de Auschwitz, é clara também a limitação da possibilidade de se mudar os pressupostos objetivos, ou seja, os pressupostos sociais e políticos que geram tais acontecimentos. $\mathrm{O}$ apelo, então, deve endereçar-se ao lado subjetivo das pessoas que fazem coisas desse tipo. O resgate das raízes das atitudes virulentas precisam ser buscadas exatamente nas pessoas que assim se comportam, ou seja, é necessário uma inflexão em direção ao sujeito. Para Adorno, a experiência de Auschwitz estabelece um novo imperativo categórico, um novo imperativo moral, universal e necessário: impedir a repetição 
de Auschwitz. Esse objetivo se projetará em seus escritos sobre educação ${ }^{5}$, já que todos os esforços de esclarecimento devem se dirigir a construir o desvio do mal, do falso, do temível de nosso mundo, traduzido pela palavra Auschwitz. Para Adorno: "É preciso reconhecer os mecanismos que tornam as pessoas capazes de cometer tais atos, é preciso revelar tais mecanismos a eles próprios, procurando impedir que se tornem novamente capazes de tais atos, na medida em que se desperta uma consciência geral acerca desses mecanismos" (ADORNO, 1995, p. 121).

Ressalte-se, por justiça, que, para Adorno, desbarbarização não se coloca como um elogio à moderação, uma restrição às afeiçoes fortes, e nem mesmo nos termos da eliminação da agressão, uma vez que compreende que os instintos de agressão podem conduzir à tendências produtivas. Na luta contra a barbárie, contudo, existe um momento de revolta, que deve ser orientado contra o princípio desta, em vez de permitir seu curso em direção à desgraça. A barbárie manifesta-se na regressão à violência física primitiva.

Entretanto, a reflexão, por si só, não garante um parâmetro frente à existência da barbárie. Um governante pode, por exemplo, se dispor ao uso de armas nucleares com base em considerações estritamente racionais e este ato pode ser bárbaro, apesar do procedimento abrangente, controladíssimo, estritamente racionalizado e não subordinado a emoções. Assim sendo, é preciso atentar para os fins que mobilizem as ações humanas, ou seja, as reflexões precisam ser transparentes em sua finalidade humana.

\section{Falência da cultura: razão objetiva da barbárie}

Antes de discutirmos a questão da falência da cultura, que a uniformiza como semiformação socializada, convém apresentarmos o conceito de formação burguesa, cuja pretensão era que os indivíduos, livres e racionais, pudessem fazer uso da vontade e do livre arbítrio em uma sociedade que asseguraria a mesma justiça e, consequentemente, as mesmas sanções para todos. ${ }^{6}$

Contudo, a cultura no capitalismo tardio, como dizem Adorno e Horkheimer na Dialética do Esclarecimento (1985) é constituída de tal forma que não chega a cumprir aquilo que prometeu: a garantia de uma sociedade racional, livre e igualitária. O ideal burguês de cultura construiu a convicção de que "cultos" são os indivíduos capazes de identificar e descrever o maior número possível de dados da realidade concreta. Dessa maneira, cultura implicaria na total identificação entre espírito e realidade. Na análise adorniana do duplo caráter da cultura faz-se notória a objeção referente à identificação do espírito à realidade. No que diz respeito a essa objeção, Adorno critica a total transformação do conceito de cultura em um valor, a ponto de se desconsiderar o vínculo existente entre a produção cultural e a sociedade.

A total absolutização do momento de adaptação dos homens à realidade resulta no maior empobrecimento das possibilidades de emancipação e os aprisiona

${ }^{5}$ Conferir a obra Educação e Emancipação. Tradução de Wolfgang Leo Maar. Ed. Paz e Terra. Rio de Janeiro, 1995.

${ }^{6}$ No texto Sobre o caráter afirmativo da cultura, Herbert Marcuse (1997) elabora uma série de reflexões que auxiliam no aprofundamento da questão da necessária coexistência entre o impulso e a cultura, a qual se revela justamente como centro estruturador da categoria formação.

ROCHA, Cleidson de Jesus. Educação e emancipação na teoria crítica da sociedade de Theodor W. Adorno. Griot : Revista de Filosofia, Amargosa - BA, v.19, n.2, p.194-217, junho, 2019. 
aos esquemas subjetivos favoráveis à manutenção do estado febril de paralisação espiritual e cultural, propício à realização da barbárie contra a qual Adorno dedica grande parte de seu esforço intelectual. Assim diz Adorno

[...] existe uma razão objetiva da barbárie, que é (...) a falência da cultura $[\ldots]$ a cultura, que conforme sua própria natureza promete tantas coisas, não cumpriu a sua promessa. Ela dividiu os homens. A divisão mais importante é aquela entre trabalho físico e intelectual. Deste modo ela subtraiu aos homens a confiança em si e na própria cultura. E como costuma acontecer nas coisas humanas, a consequência disto foi que a raiva dos homens não se dirigiu contra o não-cumprimento da situação pacífica que se encontra propriamente no conceito de cultura. Em vez disto, a raiva se voltou contra a própria promessa negada, expressandose na forma de que essa promessa não deveria existir. (ADORNO, 1995, p. 164)

Devemos lembrar com Sérgio Paulo Rouanet (1987, p. 331) que o conceito de razão em Adorno comporta uma complexidade expressa em três níveis: primeiro, significa uma razão que continua exercendo sua atividade mesmo depois de ter perdido todo direito à existência, definindo-se pelo processo de racionalização e de reificação, funcionando como prática de liberdade e agente de dominação. Segundo, a razão moderna é entendida como aporética, porque utiliza as armas da razão para denunciar a própria razão, opondo-se a si mesma, o que pode desqualificar sua própria crítica. $O$ terceiro problema decorrente da compreensão de Adorno quanto à razão é que pretende chegar ao não conceitual através do próprio conceito, o que significa comportar-se negativamente, como preceitua a dialética negativa.

$O$ fato de a humanidade não ter conseguido maneiras de lidar com a razão, fez com que esta se transformasse em seu contrário. Em vez da afirmação de uma humanidade liberta da opressão, o que se verifica, segundo Adorno, é uma sociedade que se organiza a partir de uma razão instrumental, que tem por base não o esclarecimento, mas a semiformação.

Uma possibilidade de transformação desse quadro se processa mediante o esclarecimento das situações de falência da cultura e das razões de perpetuação socialmente impositiva da barbárie. Essa questão, se levada de um modo abrangente à consciência das pessoas, seguramente poderá gerar um clima favorável a uma modificação do quadro vigente. Isso para Adorno é decisivo, pois sua luta contra a barbárie não implica, de maneira nenhuma, numa "conversão de todos os homens em seres inofensivos e passivos. Ao contrário: esta passividade inofensiva constitui ela própria, provavelmente, apenas uma forma de barbárie, na medida em que está pronta para contemplar o horror e se omitir no momento decisivo" (ADORNO, 1995, p. 164).

A impossibilidade da razão de traduzir adequadamente a situação contemporânea, já que encontra-se corroída pelo espírito da semiformação, soma-se à insuficiência da própria linguagem, que por mais que tente, não consegue expressar o terror que foi a experiência nos campos de concentração nazistas. Por isso, mesmo a simples descrição do que os nazistas fizeram com os judeus não é tarefa fácil. Na tentativa de caracterizar, a um só tempo, o que seja a morte em massa, sem propósito, e aquelas que resultam das guerras, alguém, não se sabe 
quem, cunhou o termo "holocausto". Christopher Lasch (1987) assim se refere a esse esforço de evidenciar o significado do termo:

[...] não está claro quem propôs pela primeira vez o termo, mas este foi adotado, com toda a probabilidade (e não apenas pelos judeus), na esperança de que diferenciasse os atos de monumental desumanidade das matanças e das guerras rotineiras, e mesmo de outros incidentes de assassinato em massa. O rótulo carrega consigo a implicação de que aquilo que os nazistas fizeram contra os judeus permanece um fato único [...] (LASCH,1987, p. 89).

Desde então, a linguagem busca descrever esse acontecimento aterrador e captar a sua ferocidade. Apesar dos esforços descritivos, essa linguagem

[...] não pode ser transformada em rotina, a menos que assassinato a sangue-frio se transforme ele próprio em rotina. [..] A verdade é que as palavras fracassam frente a tal perversidade. Como disseram tantos sobreviventes, o silêncio é o único tributo adequado [...] aos milhões de homens inocentes. Especificar ou regatear números é decididamente indigno. As palavras fracassam, e, no entanto, é necessário falar. $O$ silêncio é, entretanto, opção dos fracos, que nele se acovardam ou por inteiro acordo com o estado de coisas atual, ou por incapacidade de expressar, de forma articulada, a crítica pertinente aos acontecimentos do presente (LASCH, p. 90).

Adorno intima à conscientização da barbárie e faz um apelo para que se "volte ao sujeito" de tal horror:

As raízes têm de ser procuradas nos perseguidores, não nas vítimas que, sob os mais mesquinhos pretextos, foram entregues aos assassinos. [...] Deve-se conhecer os mecanismos que tornam os homens assim, que os tornam capazes de tais atos. Deve-se mostrar esses mecanismos a eles mesmos e buscar evitar que eles se tornem assim novamente, enquanto se promove uma conscientização geral desses mecanismos (ADORNO, 1995, p. 121).

As tendências desagregadoras de nossa sociedade se evidenciam na pressão do geral predominante sobre o particular, nos indivíduos e instituições que tendem a desintegrar o particular e o individual juntamente com sua capacidade de resistência, sob a égide dos meios de comunicação. Eles cuidam da assimilação dos homens, isolando-os. Esse isolamento, contudo, não se dá apenas no âmbito cultural:

A afirmação que o meio de comunicação isola não vale apenas no domínio cultural. Não apenas a linguagem mentirosa do locutor de rádio se sedimenta no cérebro das pessoas como a imagem da linguagem e impede-nos de falar umas com as outras, não apenas o louvor da PepsiCola abafa o ruído espectral dos heróis do cinema e se projeta sobre o abraço dos adolescentes e mesmo sobre o adultério. $O$ progresso separa literalmente as pessoas [...] (ADORNO e HORKHEIMER, 1985, p. 206). 
O progresso separa as pessoas também fisicamente. Famílias inteiras confinam-se em enormes edifícios, fechados entre as quatro paredes de apartamentos incomunicáveis uns com os outros, onde a estrutura de cimento é responsável pela privacidade; as pessoas viajam em conduções próprias, privandose de transportes coletivos; compras são efetuadas pelo telefone e internet, sendo desnecessário o contato com feiras e supermercados. Esse isolamento é característico da Sociedade Industrial. Essa, como tal, tem suas leis. Uma delas define e sistematiza os padrões culturais. Para bem servir a uma sociedade industrial, serve somente a fidelidade ao modelo por ela mesma produzido.

$\mathrm{Na}$ indústria cultural convergem expressões e meios construindo uma "racionalidade técnica" que visa à dominação sistemática dos grupos. Assim, ela não atende necessidades básicas da comunidade, mas ao contrário, empenha-se em criar necessidades que são por ela mesma preenchidas. A indústria cultural, assim, é violenta, no sentido de que a todos atinge e condiciona por seus princípios. "Cada qual é um modelo da gigantesca maquinaria econômica que, desde o início, não dá folga a ninguém, tanto no trabalho quanto no descanso, que tanto se assemelha ao trabalho" (ADORNO e HORKHEIMER, 119). Na indústria cultural divertir-se significa "estar de acordo". O sofrimento é simulado pelo esquecimento de que se sofre. O homem, assim, nada mais é do que um ser genérico. "Cada homem é tãosomente aquilo mediante o que pode substituir todos os outros; ele é fungível, um mero exemplar. Ele próprio enquanto indivíduo é absolutamente substituível, o puro nada" (ADORNO e HORKHEIMER, p. 136).

A indústria cultural extraiu do homem a possibilidade do Eu soberano. Dálhe, sem alternativa, somente o direito de ser cliente e empregado - e, de fato, consegue "reduzir a humanidade inteira, bem como cada um de seus elementos, a essa fórmula exaustiva" (ADORNO e HORKHEIMER, p. 137). É a imposição de uma pretensa verdade, que embora não sendo um costume, possui uma autoridade "espiritual". Hoje, como estamos vendo, a ideia da maioria, privada de seus fundamentos racionais, assume um aspecto complemente irracional, já que sua cultura é produzida tendenciosamente por uma máquina - a indústria cultural.

O funcionamento da indústria cultural requer esquemas de transmissão cultural efetivamente industriais, no sentido da estandardização e racionalização das técnicas produtivas e de distribuição. A lógica desse esquema assenta-se no nivelamento, visando um rendimento ótimo que aproxime de imediato consumidor e produto. Essa aproximação tem como ponto o prazer do entretenimento. $O$ produto assim embalado coloca-se como objeto de desejo, é sentido como necessidade prática e passa a ter utilidade como bem de consumo. Transforma-se, pois, em fetiche.

Para Adorno, com a indústria da cultura, o próprio conceito de gosto, que permitiria uma escolha pessoal entre os produtos oferecidos, está ultrapassado; a escolha é quase uma falácia; o gostar e o não gostar já não correspondem a um estado real, desde que, em vez do valor da própria coisa, o critério de julgamento se baseia no padrão mais difundido: o mais conhecido é o mais famoso e tem mais sucesso. Nesse sentido, a existência do próprio indivíduo torna-se problemática, pois ele não consegue mais vivenciar completamente a própria liberdade de escolha; 
a produção padronizada dos bens culturais oferece praticamente os mesmos produtos a todo cidadão.

Essas afirmações de Adorno embasam seu conceito de regressão como anverso da cultura-fetiche, que não corresponde a um retrocesso do nível coletivo geral, mas à perda da capacidade de um conhecimento consciente da cultura pelo indivíduo que foi sendo privado de sua liberdade de escolha.

\section{Reflexos da vida danificada: o adoecimento do contato}

Para Adorno (1985) o sonho de uma época esclarecida e livre das mazelas produzidas pelas experiências sociais do homem não se constitui como realidade plena. $O$ esclarecimento que, segundo os iluministas ajudaria na construção de uma vida mais feliz, não realizou essa promessa. Kant, contrapondo-se à ideia iluminista do conhecimento como chave para a resolução dos problemas do homem, compreendia que o esclarecimento deveria ser visto não como resultado fechado da busca por verdades, mas como processo, como busca, aprendizagem. $O$ pensamento pedagógico, em boa parte herdeiro dessa concepção, aí se apoia, crente de que a humanidade pode alcançar novos rumos no processo de desenvolvimento, a partir do conhecimento e da educação dos homens.

Segundo Adorno (1993), a razão instrumental se fez mundo, mas o mundo não se fez razão; ao contrário, tornou-se irracional. Esse quadro abrange toda a sociedade, contaminando também as instituições que por definição deveriam se voltar para a produção da negação desse estado de coisas, como a escola, por exemplo.

A crítica de Adorno a essa situação, não pode ser ignorada pelos educadores no tempo de perplexidade em que vivemos, em que a falta de capacidade de argumentação e de reflexões, faz com que se verifique entre os homens uma grande falta de entendimento. Percebe-se a perda que todos demonstram do diálogo, da conversa, da escuta do outro. Temos observado os vários ramos do saber, como a história, a sociologia, a psicologia, a psicanálise, a antropologia, as ciências humanas enfrentando debates sobre a ideia de um outro, numa busca instigante por saídas para a humanidade.

Essa busca ainda não dá sinais de que esteja esmaecendo o clima de discriminação, de exclusão e de eliminação do outro. Ainda nos assombramos com a constatação de que, em que pese o avanço ou o aparente progresso que o homem foi e vem sendo capaz de conquistar, a humanidade não deu conta de enfrentar e superar o problema que está na origem dos grandes crimes cometidos contra a vida - sejam eles de ordem política, étnica, religiosa, social, sexual - na origem de todos os genocídios: a dificuldade de aceitar que somos feitos de pluralidade, pois o que nos singulariza como seres humanos é justamente nossa diferença.

A filósofa espanhola Amélia Valcársel (2001) faz uma constatação intrigante. Segundo ela, é seu costume observar que, "por menores que sejam, os jardins públicos ficam repletos de cães ao anoitecer". (2011, p. 7). Valcársel afirma ter percebido que 
samoiedo cheira um alsaciano, um setter trava uma longa conversação com um terrier, e até mesmo um grande dinamarquês se junta a um chihuahua para farejar. Se não soubéssemos que todos esses animais pertencem à mesma espécie, seria difícil imaginá-lo. São muito diferentes em cor, tamanho, força e forma. Entretanto, reconhecem-se. Quer seja pelo idioma quase universal do latido, por movimentos e odores, ou talvez por razões mais misteriosas, nenhum cão parece confundir um outro com um gato, uma raposa ou um mico. Cheiram-se, brincam entre si, perseguem-se, e às vezes, atacam-se. Mas se reconhecem. (VALCÁRSEL, 2011, p. 17)

Com esta curiosa observação, Valcársel (2011) ensaia uma análise da filosofia moral e política do século XX, constatando que "o cálculo da alteridade" foi para o este século um problema. Até agora não conseguimos "reconhecer no outro um semelhante". Diz a autora que, embora existam tão poucas diferenças entre os homens,

[...] tons de marrom na pele, uma pequena gama de castanhos no cabelo e um par de tonalidade de íris, mesmo com uma base tão sucinta, falamos de raças humanas. Brancos, amarelos, vermelhos, negros e "azeitonados", entre os quais os antropólogos do início do século XX distinguiram subgrupos. A colonização total do planeta encheu as enciclopédias de gravuras de seres humanos "diferentes”. (VALCÁRSEL, 2001, p. 18)

Esse cenário está bem retratado na obra de T. W. Adorno, que realiza uma aguda e sensível crítica à sociedade contemporânea e à educação, culminando em sua defesa de uma educação contra a barbárie, para que Auschwitz não se repita. Ressalte-se que, para Adorno e Horkheimer (1985), as condições objetivas que empurram a humanidade para a barbárie já são a própria barbárie, e não somente seus resultados mais terríveis.

A sociedade atual é descrita por Adorno como "sociedade administrada". Nessa configuração, é o espaço em que o indivíduo se encontra envolvido nas estreitas malhas da alienação e da socialização impessoal. Tal sociedade provoca nas pessoas um sentimento de claustrofobia, uma sensação de encontrar-se enclausurado numa situação cada vez mais complexa, como uma rede densamente interconectada. Quanto mais densa é a rede, mais se procura escapar, ao mesmo tempo em que precisamente a sua densidade impede a saída. Isso aumenta a raiva contra a civilização. Esta torna-se alvo de uma rebelião violenta e irracional.

Neste tipo de sociedade, pensar é um ato de coragem, de posicionamento. Só pensa quem não se limita a aceitar passivamente o que está dado. É mais tranquilo dar braçadas a favor da correnteza, mesmo quando se declara contra a correnteza. As mentes que ainda não foram completamente modeladas pela socialização impessoal, apenas elas têm condições de resistir à pressão avassaladora.

A sociedade administrada resulta do exercício da razão instrumental. Esta, por sua vez, é razão no processo técnico, na operação, no saber aplicado. Eliminando toda dubiedade do pensar através da unidimensionalidade, ela se torna a ferramenta das ferramentas a serviço da produção material, da exploração do trabalho, dos trabalhadores. Seu objetivo é a reprodução ampliada do capital. $O$ 
velho sonho de usar a ciência para explorar racionalmente a natureza a serviço da humanidade continua sendo um sonho. Os homens devem aprender a dominar complemente a natureza e através dela dominar os homens. Para Adorno, nos dias de hoje o que importa não é aquela satisfação que os homens chamam de verdade, o que importa é o proceder eficaz.

Em Mínima Morália, por exemplo, Adorno discorre sobre as dificuldades enfrentadas por aqueles que, sendo filhos de pais abastados, "escolhe uma das profissões intelectuais" (Adorno, 1993, p. 15). Segundo o frankfurtiano, esses profissionais geralmente têm posta em dúvida sua seriedade. E isso decorre do ressentimento daqueles que "levam o desagradável nome de colegas", (ADORNO, 1993, p. 15) que já não conseguem escapar ao clima de dissimulação que contamina a sensibilidade contemporânea:

\begin{abstract}
A ocupação com coisas espirituais tornou-se, entrementes, ela própria uma atividade 'prática', um negócio marcado pela rígida divisão do trabalho, com ramificações e numerus clausus. Encontra-se em voga uma tal departamentalização do espírito, que é um meio de isolar os espíritos [investigativos], e este meio faz com que uns poucos sigam fazendo seu serviço com segurança tanto maior quanto mais aquele que rompe com a divisão do trabalho revela, na medida mesmo deste prazer, pontos vulneráveis no seu fazer. (ADORNO, 1993, p. 15)
\end{abstract}

Para Adorno isso expressa o zelo pela manutenção da ordem social vigente: "[...] uns têm que se conformar porque, de outro modo, não podem viver; outros, que poderiam viver de outro modo, são deixados de fora porque não querem se conformar. É como se a classe desertada pelos intelectuais independentes se vingasse na medida em que as suas exigências se impõem forçosamente lá onde o desertor busca refúgio" (ADORNO, 1993, p. 16). As instituições da sociedade administrada estão também comprometidas. Na família, por exemplo, segundo Adorno,

[...] o relacionamento com os pais começa a ficar cheio de sombras. Por impotência econômica, eles perderam o temor que infundiam [...]. A geração que encontramos, diz Adorno, embora supostamente jovem, em cada uma de suas reações é insuportavelmente mais adulta que seus pais o foram. Esta geração já se resignou antes mesmo de ter entrado em conflito e daí extrai seu poder de maneira encarniçadamente autoritária e inabalável (ADORNO, 1993, p. 16).

Embora resignados, os jovens primam pela afirmação dos antagonismos visíveis entre eles e a geração de seus pais, com quem estabelecem concorrências. Na tentativa da afirmação de seus valores e convicções se localiza a violência pura e simples. Dos pais para com os filhos enquanto se desobrigam das afirmações de códigos de ética que se projetem sobre a vida de todos os membros da família, e dos filhos para com os pais enquanto se rebelam na não aceitação das racionalizações de antigamente, que, embora escondessem verdades, anunciavam um pressentimento da verdade, um impulso para a conciliação do conflito. A geração atual renega esse pressentimento. Para Adorno: 
[...] mesmo o espírito distraído, inconsequente e desconfiado de si mesmo dos mais velhos ainda é mais acessível do que a estupidez escaldada do júnior. Mesmo as extravagâncias e as deformações neuróticas dos adultos velhos representam ainda o caráter, algo humanamente realizado, comparada ao rigor pático, ao infantilismo elevado à norma (ADORNO, 1993, p. 16).

Vivemos numa época em que as ordenações da vida, que se apresentam como se favorecessem o homem, concorrem, na economia do lucro, para atrofiar o que é humano, e quanto mais elas se estendem, tanto mais podam tudo o que é delicado. A delicadeza entre os seres humanos é descrita por Adorno (ADORNO, 1993, p. 34) como "a consciência da possibilidade de relações isentas de interesse, consciência essa que perpassa até mesmo aqueles que se prendem a interesses". Os envoltórios que poderiam embelezar e suavizar a vida humana, os gestos de delicadeza, são sentidos como perturbação do funcionamento da máquina. Estamos contaminados por uma doença do contato. Adorno descreve assim essa patologia contemporânea:

O fato de que, ao invés de tirar seus chapéus, se cumprimentem com o 'Olá!', de familiar indiferença, e de que em vez de cartas se enviem inter Office communications, sem tratamento nem assinatura, são sintomas de um adoecimento do contacto. A alienação manifesta-se nos homens precisamente no fato de que as distâncias são eliminadas. Pois, é só enquanto não se importunam uns aos outros com coisas como dar e tomar, discutir e executar, dispor e funcionar, que sobra espaço suficiente entre eles para os delicados laços que os ligam uns aos outros, em cuja exteriorização, somente, o que é interno pode cristalizar-se (ADORNO, 1993, p. 34).

Vemos aqui a crítica adorniana à escolha por um mundo piorado, em que as instituições, mesmo as mais tradicionais como a família, veem-se corrompidas e vitimadas por uma evasão de seus membros que se retiram para uma rede confusa de relações inferiorizadas, perdendo a oportunidade de refazer a vontade de uma outra sociedade. Sem a família, desfaz-se, para Adorno, não somente a mais eficaz instituição burguesa, mas a resistência, que decerto reprimia o indivíduo, mas também o reforçava, se é que não o produzia pura e simplesmente. Com a fim da família, esvai-se também mais uma possibilidade da ação dos sujeitos, paralisando as forças de oposição. “(...) A ordem coletivista nascente é um escárnio para os semclasse; com o burguês liquida-se ao mesmo tempo a utopia que outrora se nutria do amor da mãe" (ADORNO, 1993, p. 17).

Da mesma forma, as trocas de cordialidade estão desaparecendo. As pessoas estão desaprendendo os princípios da civilidade cordial. "Não se aceitam trocas" (ADORNO, p. 35). O gesto de presentear foi violado. Muitas vezes, segundo Adorno, até as crianças examinam com desconfiança quem dá algo, como se o presente fosse apenas uma desculpa para vender-lhes algum produto recém-lançado no mercado. Corrompe-se, assim, até mesmo o ato privado de dar presentes. Este "foi rebaixado ao nível de uma função social que se efetua com uma racionalidade contrariada, com base no cumprimento cuidadoso de um budget estipulado, numa avaliação céptica acerca do outro e com o menor esforço possível" (ADORNO, p. 35). 
Os indivíduos, assim, desprotegidos, caem numa rede de interesses, aparelhada pela indústria. Esta, altamente concentrada, substitui a esfera da circulação, ocupando-se também da geração de uma consciência pasteurizada, homogênea, que se reforça enquanto reproduz os interesses desta mesma indústria. A base econômica desvanece, assim, das ocupações intermediárias. Inicia-se, então, o espantoso tempo da pós-existência. Subsume-se o indivíduo, enquanto identidade, numa entrega aos caprichos industriais:

[...] a vida privada de inúmeros indivíduos torna-se uma vida de agentes e mediadores, o domínio do privado como um todo é devorado por uma enigmática operosidade que apresenta todos os traços da atividade comercial, sem que nela haja propriamente algo para comerciar. (ADORNO, 1993, p. 17).

Muito embora o conceito de emancipação seja um tema caro às tradições críticas, para Adorno (1995a, p. 143) "a ideia de emancipação é, ela própria, ainda demasiado abstrata, além de encontrar-se relacionada a uma dialética. Esta precisa ser inserida no pensamento e também na prática educacional". Adorno enxerga dois problemas que é preciso levar em conta quando se trata de emancipação.

\footnotetext{
Em primeiro lugar, a própria organização do mundo em que vivemos e a ideologia dominante, pois a organização do mundo converteu-se a si mesma, imediatamente, em sua própria ideologia. Ela exerce uma pressão tão imensa sobre as pessoas, que supera toda a educação. Seria efetivamente idealista querer-se combater o conceito de emancipação sem se levar em conta o peso imensurável do obscurecimento da consciência pelo existente. Em segundo lugar [...] de um certo modo, (para Adorno) emancipação significa o mesmo que conscientização, racionalidade. Mas a realidade sempre é simultaneamente uma comprovação da realidade, e esta envolve continuamente um movimento de adaptação (ADORNO, 1993, p. 143).
}

É difícil, portanto, para um homem em particular desvencilhar-se da menoridade que para ele se torna quase uma segunda natureza. A constituição e a aceitação de "vínculos" dão ao indivíduo o direito de exigir uma autoridade que cuide dele e da nação. Contudo, para Adorno, é precisamente a disposição de aderir ao poder e, externamente, submeter-se passivamente aquilo que é mais forte - à mentalidade dos algozes-, o que se deve combater para bloquear a possibilidade de um ressurgimento de fatos como os de Auschwitz.

Dessa forma, para Adorno, a recomendação do "vínculo" é algo fatal. As pessoas que o aceitam mais ou menos voluntariamente passam a encontrar-se numa espécie de constante estado de crise de soberania. A única verdadeira força contra o princípio de Auschwitz seria a autonomia. Tal autonomia só seria adquirida através do esclarecimento. Esse, contudo, só muito lentamente pode chegar a um público. Um fator sem o qual o esclarecimento torna-se inviável é a liberdade; não a liberdade que oferece a indústria cultural, mas aquela que permita fazer um uso público de sua razão em todas as situações.

Para Adorno, a medida mais importante contra o perigo de uma repetição (de Auschwitz) é contrapor-se a qualquer supremacia coletiva cega e aumentar a 
resistência contra ela, desviando-se da prerrogativa da coletivização. A experiência da coletividade é uma experiência agressiva, pois a individualidade é condensada em função do coletivo, o eu arremessado para o nós, em cuja situação lhe é negado o direito à diferença. Dessa forma, se esvai a possibilidade da manifestação de uma identidade própria, com todas as suas particularidades, inclusive o direito ao medo. Para Adorno o direito ao medo deve ser assumido conscientemente pelo indivíduo. "Quando o medo não for reprimido, quando nos permitirmos ter tanto medo real quanto essa realidade merecer, então possivelmente muito do efeito destrutivo do medo reprimido desaparecerá". (ADORNO, 1993, p. 129)

Contudo, assumir esse medo não é tarefa fácil, pois ao fazê-lo, o indivíduo divorcia-se da comunidade que só o aceita enquanto igual a todos os outros membros. Na sociedade industrial o indivíduo só é tolerado na medida em que sua identidade com o universal está fora de questão. O indivíduo é fungível, é igual a todas as coisas, idêntico ao coletivo. Nessa condição opera apenas como um algo, como um material, dissolvendo-se como ser autodeterminado. Isso combina, como diz Adorno, com a disposição de tratar os outros como uma massa amorfa. Para os que se comportam dessa maneira, Adorno utilizou o termo "caráter manipulador". É próprio do caráter manipulador a "fúria organizativa", a "incapacidade total de levar a cabo experiências humanas diretas", um "tipo de ausência de emoções", "um realismo exagerado". Adorno segue ainda sua descrição dizendo:

\begin{abstract}
A qualquer custo ele procura praticar uma pretensa, embora delirante, realpolitik. Nem por um segundo sequer ele imagina o mundo diferente do que ele é, possesso pela vontade de doing things, de fazer coisas, indiferente ao conteúdo de tais ações. Ele faz do ser atuante, da atividade, da chamada efficiency enquanto tal, um culto, cujo eco ressoa na propaganda do homem ativo. Este tipo encontra-se, entrementes [...] muito mais disseminado do que se poderia imaginar. $\mathrm{O}$ que outrora era exemplificado apenas por alguns monstros nazistas pode ser constatado hoje a partir de casos numerosos, como delinquentes juvenis, líderes de quadrilhas e tipos semelhantes, diariamente presentes no noticiário. Se fosse obrigado a resumir em uma fórmula esse tipo de caráter manipulador [...] eu o denominaria de o tipo da consciência coisificada. Em seguida, na medida em que o conseguem, tornam os outros iguais a coisas (ADORNO, 1995, p. 129-130).
\end{abstract}

Para Adorno, qualquer providência ou tentativa de se atuar contrariamente à repetição de Auschwitz, exige a produção de uma certa clareza acerca do modo de constituição do caráter manipulador, para em seguida poder impedir da melhor maneira possível a sua formação pela transformação das condições que a geram. Para tanto, propõe:

(A) Que se utilize todos os métodos científicos disponíveis, em especial a psicanálise durante muitos anos, para estudar os culpados por Auschwitz, visando, se possível, descobrir como uma pessoa se torna assim. Com isso se eliminaria a dita "consciência coisificada".

(B) Que se observe a relação do indivíduo com a técnica, pois a tecnologia do mundo atual produz pessoas tecnológicas, que, tendo o amor absorvido pelos objetos, usam toda sua capacidade de amar (esgotada) em coisas materiais. 
Dessa forma, essas pessoas passariam a ser menos influenciáveis, com as correspondentes consequências no plano geral.

Adorno ressalta ainda que a conscientização dos mecanismos subjetivos é possível. Se o esclarecimento racional com base na psicologia não dissolve diretamente o mecanismo inconsciente, pelo menos fortalece na pré-consciência determinadas contra instâncias e ajuda a superar um clima favorável aos extermínios. Esse processo de tomada de consciência, só pode ser resultado, entretanto, do enfrentamento corajoso dos "fantasmas" que comprometem a qualidade das relações entre os homens. A frieza imperante, que faz com que as pessoas sejam profundamente indiferentes em relação ao que acontece com todas as outras precisa ser combatida, pois hoje a sociedade não mais

[...] repousa em atração, em simpatia, como se supôs ideologicamente desde Aristóteles, mas na persecução dos próprios interesses frente aos interesses dos demais. Isso se sedimentou do modo mais profundo no caráter das pessoas. $\mathrm{O}$ que contradiz o impulso grupal da chamada lonely crowd, da massa solitária, na verdade constitui uma reação, um enturmar-se de pessoas frias que não suportam a própria frieza mas nada podem fazer para alterá-la (ADORNO, 1995, p. 134).

Essa necessidade de tomada de consciência a respeito do estado de frieza que se arraigou na sociedade contemporânea não significa, para Adorno, uma pregação do amor, pois, segundo este autor

[...] sua pregação é vã: ninguém teria o direito de pregá-lo, porque a deficiência de amor [...] é uma deficiência de todas as pessoas, sem exceção, nos termos em que existem hoje. Pregar o amor pressupõe naqueles a quem nos dirigimos uma outra estrutura do caráter, diferente da que pretendemos transformar. Pois as pessoas que devemos amar são elas próprias incapazes de amar e por isto não são tão amáveis assim (ADORNO, 1995, p. 134-135).

No regime nazista o árbitro humano mostrou-se capaz de atentar contra sua própria liberdade, motivo pelo qual não se pode desconhecer essa criação histórica. O desconhecimento, se coincidentemente realizado, só pode vir a ser um fator que contribuirá para o desenvolvimento de condições nas quais um fenômeno como aquele poderá novamente ocorrer. Ele significaria um apagar da memória o acontecido, daí resultando a destruição de nossa capacidade política de julgar, abrindo caminho para a consequente banalização dos males que afligem a nossa sociedade, dentre os quais a miséria gritante de muitos. Será somente por intermédio do despertar da subjetividade individual que cada indivíduo poderá vir a estar atento às vicissitudes de sua época, ou ainda, a tentativas sempre presentes de uma mera instrumentalização da política, de paralisia e da eliminação do senso comum.

Esses procedimentos de conscientização apontados por Adorno supõem, obviamente, o critério da crítica. Esta se realiza como resistência contra tudo o que é estabelecido e que se justifica apenas pelo Dasein. A aceitação da realidade como 
se apresenta ao sujeito contribui para a manutenção do establesment, alongando o estado de coisa atual da modernidade e adiando as possibilidades do exercício da crítica. Enquanto adiam-se as operações da crítica, permite-se a integração de qualquer objeto como natural, já que há, da parte da indústria cultural, o trabalho sempre sistemático de produção da vontade. Esta vontade é produzida como necessidade de consumo, de participação, de adesão aos critérios da cultura de massa. Assim sendo, só uma crítica imanente ${ }^{7}$, caracterizada pelo inconformismo contra o que está dado e que seja capaz de descrever aquilo com o qual se confronta como ameaçador (o próprio clima cultural geral em vigor) pode assinalar a passagem do estado de adesão ao estado de não-participação. Dessa forma, a crítica é o procedimento que traz em si o incômodo, que é capaz de atiçar o ser, não deixando-o em paz.

\section{Considerações finais}

Na perspectiva adorniana a crítica só é justificada quando consegue se articular, representar. Embute-se nessa caracterização a necessidade da clareza e coerência inerente à especificidade do pensamento filosófico. Ou seja: a afirmação da crítica dá-se no plano filosófico, inicialmente. Não se trata de um discordar voluntarioso nem de um adesismo irrefletido em movimentos contestatórios do real, mas justificam-se em critérios de representatividade, isto entendido como clareza linguística, como articulação rigorosa que a linguagem científica possa representar com relação a um determinado fato. $O$ pensamento que se quer científico precisa ser compreensível porque rigoroso. Não pode, contudo, contentar-se com a simples descrição dos fatos sem articular uma sintonia entre consciências que possam vir a concordar entre si por intermédio da compreensão teórica dos fatos descritos. Essa posição de Adorno o coloca como dono de uma ânsia projetiva, que percebe a realidade e a tenta abarcar discursivamente; é na força do discurso, portanto, que Adorno faz representar a sua sofisticada elaboração crítica do mundo.

No nosso modo de ver, Adorno, neste ponto em relação aos caminhos da educação, estaria trazendo, mesmo de forma que parecesse ingênua inicialmente, uma contribuição decisiva para o que veríamos como tradução de um impasse ainda nos dias de hoje. Sua consciência inquieta, na verdade, representa uma antecipação problemática de muitas das coisas que vivemos no fio da navalha, nos chamados tempos pós-tudo.

A modernidade em Adorno é, sem dúvida, uma via de duas mãos. Sua ação, muitas vezes, depende, contraditoriamente, de um recuo estratégico. Suas posições nem sempre se encaixarão a partir de um pragmatismo possível, mas de uma medida que toca às vezes o impossível. Sua articulação de um pensamento avançado vem de uma necessidade de resistir às forças da barbárie a qualquer custo, mesmo que muitas vezes bata de frente com possíveis aliados.

Para nós, Adorno antecipa todo um estado de coisas que vivemos, hoje, cruelmente em nossa carne histórica. Desse modo, percebemos nele um gesto de

\footnotetext{
7 Segundo Jay, a crítica imanente "tem suas raízes assentadas na tradição hermenêutica de Schleiermacher e de Dilthey [e] começa com o reconhecimento de que o crítico cultural se encontra firmemente embebido da cultura que deseja criticar" (1988, p. 105)
} 
generosidade e, muitas vezes, até de impotência, que tem, sobretudo, o sentido de despertar a inquietação. Sua proposta educacional só pode ser entendida dentro de um contexto provocador, de algo que possa perfurar e remexer as coisas acabadas, dando condições do ser humano se renovar. Auschwitz é o limite que faz com que tudo se repita continuadamente, sempre como um gesto decisivo, algo que pretendemos fazer e que mudará alguma coisa no horizonte. Essa sua utopia, essa sua força.

A teoria crítica de Adorno centra-se no fato de que a ciência, a tecnologia, o conhecimento, sonhados pelos primeiros pensadores modernos como possibilidade de minorar os sofrimentos dos homens, de instrumentalizá-los para a criação de um novo mundo, vai perdendo cada vez mais seu potencial libertário, transformandose, assim, em razão instrumental. Nessa dimensão, a Razão se coloca como a negação das possibilidades emancipatórias. Sérgio Paulo Rouanet comenta assim essa situação: "o conhecimento é convertido em reconhecimento, e com a suspensão do momento reflexivo é afastado o risco de que o sujeito coloque no real algo que, de início, já não estivesse nele" (ROUANET, 1986, p. 147).

A racionalidade técnica se torna a racionalidade da dominação, enquanto mero reconhecimento. Saber e conhecimento, nessa perspectiva, são sinônimos de poder, de um poder tão universal e onipresente como o é a razão instrumental. $O$ mundo inteiro é forçado a passar pelo filtro da indústria cultural. O processo fatal da racionalidade penetra todos os aspectos da vida cotidiana, subordina todos os setores da vida espiritual a um único fim, ou seja, "ocupar os sentidos dos homens da saída da fábrica à noitinha, até a chegada ao relógio do ponto na manhã seguinte" (ADORNO e HORKHEIMER, 1985, p. 123). A diversão se torna um prolongamento do trabalho no sistema capitalista mais desenvolvido. E assim, a indústria cultural cumpre perfeitamente suas funções particularmente úteis ao capital: reproduz a ideologia dominante ao ocupar continuamente com sua programação o espaço de descanso e de lazer do trabalhador; vende-lhe os produtos culturais da mesma maneira que lhe vende os bens de consumo; difunde por todos os cantos a pseudodemocrática ideologia do vendedor, do acesso fácil a todos os bens espirituais enquanto mercadorias. Todos os homens são transformados em seus clientes e empregados preferenciais (ADORNO e HORKHEIMER, p. 137).

Os defensores de que a ciência exerça um papel cognitivo emancipador contaram com alguns acontecimentos da história real para justificar suas motivações epistemológicas. Os argumentos do "fim da ideologia", vindos da sociologia, reforçam a urgência da afirmação de um pensamento engajado. Esse esforço é levado à frente pela "teoria crítica", que se propõe contestar a manipulação tecnocrática e à desativação da reflexão. Os propósitos da teoria crítica equivalem, em parte, à promoção de um movimento corretivo com vistas a intervenções que decorram da transformação do pensamento em ação, numa tentativa de impedir a potenciação da dominação do homem. Contudo a transposição desse ideário para a prática pressupõe a abstração da natureza subjetiva da sociedade. Isso impediria que os objetivos humanos da composição teórica da teoria crítica encontrem reações na prática que impedissem a sua aplicabilidade. 
O engajamento emancipador da teoria crítica, quando transposto para o plano educacional, merece alguns cuidados: o primeiro deles opera no plano da subjetividade. Os atores da cena pedagógica precisam atuar na perspectiva de uma constante reordenação do espaço onde operam. Uma vontade de mudança, um desejo de transformação precisa ser configurado como ponto de partida para o fazer pedagógico. Um segundo ponto decorre deste: da vontade de mudança deve-se construir mecanismos de desvio da tendência empírico-analítica, puramente tecnológica, densa em possibilidades de adestramento. Assim, livre do caráter manipulador, a pedagogia pode, com os auspícios da teoria crítica, alcançar seu modo corretivo emancipador. Na base desse projeto, o trabalho educativo se reveste do viés emancipatório.

No debate sobre o papel do conhecimento, aprofundado pela ciência, há que se levar em conta o uso que os seres humanos fazem desta e da técnica, ou, dito de outra maneira: a função emancipadora da ciência continua dependendo de como as pessoas conseguem institucionalizar suas relações sociais, em correspondência com o domínio tecnológico sobre a natureza. Temos visto vários atestados de perversão da função emancipadora da ciência (sua usurpação militar, com a bomba atômica como seu exemplo mais dramático), ou no plano político, o modelo estatal tecnocrático. O que não se pode é assumir o plano romântico da utopia, esquecendo-se que as pessoas são ao mesmo tempo sujeitos e objetos das ciências. Dessa maneira, sob os profissionais do conhecimento deve ressoar o compromisso da construção de um acordo mútuo intersubjetivo quanto a fins e valores.

O processo de globalização da economia, a sociedade de consumo e a sociedade de informação produzem um tempo de mutações aceleradas, mas também, paradoxalmente, um período de estagnação e novas alianças, algumas delas eminentemente conservadoras. Nesse cenário cabem às instituições o reerguimento das potencialidades humanas. Para Adorno, a recuperação da razão enquanto instrumento de esclarecimento e autonomia é a chave para a saída do homem desse estado de coisas. Esta recuperação não se dará sem um projeto emancipatório, assumido por homens dispostos a se contrapor ao gigantesco esquema de dominação organizado pela indústria cultural. Por outro lado, não basta à vontade de lutar, mas faz-se imprescindível o comprometimento engajado de reelaborar os esquemas conceituais para que os indivíduos se tornem sujeitos, e assim, autônomos.

Segundo Antônio Álvaro Zuin (1998, p. 120) “educação significa emancipação". Assim configurada, a educação não pode processar-se como discurso unilateral, nem pode haver acordo possível que não pressuponha negociação, orientada por um processo de reflexão. Há aqui, dois problemas a serem vencidos por uma pedagogia emancipadora: romper a paralisia que inviabiliza a reflexão e estabelecer estratégias de acordos mútuos entre os envolvidos com interesses formativos para que se possa alcançar as mudanças de que a realidade precisa. Essa perspectiva da emancipação que tem sua gênese na leitura crítica da realidade objetiva, só pode se constituir como prática válida, se considerar os abundantes sinais e as marcas de modificações radicais nas várias esferas da vida humana. 


\section{Referências:}

ADORNO. T. W. e HORKHEIMER, M. Dialética do Esclarecimento: fragmentos filosóficos. Trad. Guido de Almeida. Rio de Janeiro: Jorge Zahar Ed., 1985.

ADORNO, T. W. Dialética Negativa. Trad. José Maria Rispalda. Revisor Jesús Aguirre. Madrid: Taurus, 1975.

ADORNO, T. W. Educação e Emancipação. Trad. Wolfgang Leo Maar. In: Educação e Emancipação. Rio de Janeiro: Paz e Terra, 1995.

ADORNO, T. W. Introdução à controvérsia sobre o positivismo na sociologia Alemã. In: Theodor Adorno: Textos Escolhidos. Trad. Wolfgang Leo Maar. Consultoria Paulo Eduardo Arantes. S. Paulo: Nova Cultural, 1996.

ADORNO, T. W. Mínima Moralia: reflexões a partir da vida danificada. $2^{a}$ ed., S. Paulo, Ática, 1993.

ADORnO, T. W. Teoria da Semicultura. Trad. Newton Ramos-de-Oliveira com colaboração de Bruno Pucci e Cláudia Moura. In: Educação e Sociedade. Campinas-SP. Ed. Papirus, ano XVII, dez., 1996.

CASSIRER, Ernest. A Filosofia do Iluminismo. Campinas: Unicamp. 1992.

CEPPAS, Felipe. Formação filosófica e crítica: Adorno e o ensino de filosofia em nível introdutório. 2003. 303 f. Tese (Doutorado em Educação) - Pontifícia Universidade Católica do Rio de Janeiro, Rio de Janeiro.

GUR-ZE'EV, Ilan. http://www.consciencia.net/2004/arquivo/boletim4.html. Acesso em 03/03/2019.

GUR-ZE'EV. Ilan. Toward a disporic education: multi-culturalism, post-colonialism and conter-education in post-modern. Tel-Aviv, Israel. Resling (Hebrew), 2004.

HABERMAS, Jürgen. O entrelaçamento de mito e esclarecimento. In: O Discurso Filosófico da Modernidade. S. Paulo: Martins Fontes, 2000.

JAY, Martin. As ideias de Adorno: Trad. Adail Ubirajara Sobral. S. Paulo: Cultrix: Editora da Universidade de S. Paulo, 1988.

KANT, I. Resposta à pergunta: “Que é esclarecimento?”. In: Textos Seletos. Petrópolis: Vozes, 1985.

LASCH, Christopher. O mínimo eu: sobrevivência psíquica em tempos difíceis. Trad. João Roberto Martins Filho. Brasiliense: S. Paulo, 1990.

LEVI, Primo. Os afogados e os sobreviventes. Trad. Luiz Sérgio Henriques. S. Paulo. Paz e Terra, 2004.

LEO MAAR. A Formação em questão: Lukács, Marcuse e Adorno. A Gênese da Indústria Cultural". In: A Educação Danificada: contribuições à teoria crítica da educação / Organizadores Antônio Álvaro Zuin, Bruno Pucci, Newton Ramos-deOliveira. Petrópolis, RJ: Vozes; São Carlos, SP: Universidade Federal de São Carlos, 1997.

ROUANET, Sérgio Paulo. As razões do iluminismo. S. Paulo. Companhia das Letras, 1986.

VALCÁRSEL, Amélia. "Ética como valor fundamental". In: Ética e Cultura. Danilo Santos de Miranda (Org). S. Paulo:Ed. Perspectiva: Edições SESC SP, 2011.

ZUIN, Antônio Álvaro Soares. Indústria Cultural e Educação: o novo canto da sereia. Campinas, SP: Autores Associados, 1999.

Autor(a) para correspondência: Cleidson de Jesus Rocha, Universidade Federal do Acre, Campus da floresta, estrada do canela, s/n, 69895-000, Cruzeiro do Sul-AC, Brasil. cleidson.ufac@gmail.com

ROCHA, Cleidson de Jesus. Educação e emancipação na teoria crítica da sociedade de Theodor W. Adorno. Griot : Revista de Filosofia, Amargosa - BA, v.19, n.2, p.194-217, junho, 2019. 